\title{
Balancing African Elephant Conservation with Human Well-Being in Rombo Area, Tanzania
}

\author{
Naza Emmanuel Mmbaga, ${ }^{1,2}$ Linus Kasian Munishi, ${ }^{1}$ and Anna Christina Treydte \\ ${ }^{1}$ Department of Sustainable Agriculture, Biodiversity and Ecosystem Management, School of Life Sciences and Bioengineering, \\ The Nelson Mandela African Institution of Science and Technology (NM-AIST), P.O. Box 477, Arusha, Tanzania \\ ${ }^{2}$ Department of Conservation Biology, School of Biological Sciences, The University of Dodoma, P.O. Box 259, Dodoma, Tanzania
}

Correspondence should be addressed to Naza Emmanuel Mmbaga; doreennaza@yahoo.com

Received 13 January 2017; Revised 9 April 2017; Accepted 9 May 2017; Published 31 May 2017

Academic Editor: Philippe Henry

Copyright (C) 2017 Naza Emmanuel Mmbaga et al. This is an open access article distributed under the Creative Commons Attribution License, which permits unrestricted use, distribution, and reproduction in any medium, provided the original work is properly cited.

\begin{abstract}
The critical assessment of the nature and extent of human-elephant conflict (HEC) and its impact on conservation efforts are essential if we are to meet the challenges related to extinction of local population, as well as loss biodiversity. Conservationists need detailed information on HEC in areas where these challenges prevail to improve intervention in the face of limited funds/resources. We assessed the status of HEC at Rombo area over the last six years. Data based on household surveys, focus group discussions, spatiotemporal analysis of site observations, and reported incidents of damage within the last six years were mapped. Out of all HEC cases analyzed, the most were crop damage which took place at night and the damage was severe between May and July, when cereal crops were mature. In upland areas of Rombo, HEC hotspots were observed inside the protected forest plantation where local people cultivated their annual crops. Cold spots concentrated in upland areas outside the protected forest plantation dominated by settlement and agroforestry less preferred by elephants. In lowland areas, HEC hotspots were observed in village lands close to the PAs, within settlement and farmland dominated by seasonal crops. This suggests that HEC management efforts such as establishment of buffer zones should be directed around the areas adjacent to PAs and prevention should focus on cultivation of the alternative crops and farming systems that are less preferred by elephants. Our study highlights the importance of using a combination of data collection techniques to pinpoint fine-scale HEC hotspots in a highly conflict-prone location of Tanzania.
\end{abstract}

\section{Introduction}

Conflicts between humans and wildlife are widely increasing across the world and are one of the greatest challenges to conservation of wildlife [1]. The distribution and abundance of African elephants (Loxodonta africana) is inextricably linked to that of humans [2], and anthropogenic effects on this keystone species pose serious challenges to wildlife managers, local communities, and elephants alike [3-5]. Conflict between humans and elephants is a problem throughout Africa and often leads to damage of crops and livelihoods, negative attitudes towards wildlife, and sometimes human death and injuries [6]. Human-elephant conflict (HEC) is not a new phenomenon in Tanzania and has been a serious problem since 1920s, prompting the establishment of an elephant control department [7]. However, due to an expanding human population and the increasing encroachment of people into elephant range HEC incidents greatly increased in numbers over recent times and have become a major concern $[8,9]$.

In dealing with HEC, it is important that every single (local) situation be treated as unique regardless of the human and elephant populations. This is because such conflicts affect people's livelihood differently depending on the socioeconomic and economic costs associated with the damage and destruction leading to undesirable consequences to elephant conservation. Elephant populations are at high risk (locally and globally) due to poaching and habitat loss and compounded by human population pressures, more local threats, and challenges arising from HEC which have different effects 
with different implications to the species conservation and management.

Tanzania (Mkomazi National Park [MNP], Chala Protected Area [CPA], and Kilimanjaro National Park [KINAPA]) shares elephant populations with Kenya (Tsavo West National Park [TWNP] and Amboseli National Park [ANP]) $[10,11]$. Rombo area is sandwiched between KINAPA and TWNP. Historically, elephants occurred throughout this landscape until the establishments of PAs at the beginning of the 20th century, and Rombo became an interface for elephant movements between these PAs [10]. Subsequently, man has frequently been in conflict with elephants in the area largely because of expanding human populations, demand for settlement, and crop cultivation lands. The management of elephant populations and their conflicts with people has been a matter of key concern and the mortality of unfenced populations remained high $[12,13]$. This district also is known to have rich agroecological potential, challenged by HEC [14]. However, up to now no research on HEC has been conducted in this area and Rombo's potential as a buffer zone for conservation is not known. Thus, a critical assessment of the nature and the extent of HEC and its evaluation in terms of its impact on conservation efforts are essential if we are to meet the challenges related to wildlife conservation and biodiversity loss in this area. Conservationists need to have this information at a fine spatiotemporal scale in areas where these challenges prevail to improve the intervention in the face of limited funds/resources.

Few attempts have been made up to now to produce a spatiotemporal model, which interprets the interactions between people and elephants and predicts patterns of HEC in Africa. One key prevailing model that predicts spatial patterns of HEC $[3,15]$ proposes that while temporal patterns of HEC are relatively predictable, ability to predict where HEC occurs has often not been possible. For instance, while predicting where crop raiding will occur is possible, predicting where human death or injury will occur is difficult due to variations in human and elephant population and changes in land use/cover [3]. While HEC incidents have been predicted with a spatial relationship at a coarse (large landscape $\sim 1000 \mathrm{~km}^{2}$ ) scale [3] our study encompasses interviews, site observation, and spatial analysis to investigate the nature and extent of HEC in Rombo area in an area covering half this size. This study, therefore, aimed at answering the following questions: (1) Which animal species interact with people and what role does the African elephant (Loxodonta africana) play in relation to crop raiding and human/livestock damage? (2) Where and when do the human-elephant conflict (HEC) incidents occur in Rombo area? (3) What is the trend of HEC over time and what are potential mitigation measures being used by the local communities? (4) Where are the possible HEC hotspot areas and can they be predicted? The findings of this study will greatly help in proposing better management actions by the key stakeholders (government, conservationists, and local people) so as to attain elephant conservation and livelihood development.

\section{Material and Methods}

2.1. Study Site. Our study site was Rombo area in North East Tanzania $3^{\circ} 09^{\prime} \mathrm{S}$ and $37^{\circ} 33^{\prime} \mathrm{E}$ [14], which lies between three protected areas, namely, KINAPA on the northwest and CPA and TWNP on the southeast (Figure 1) covering approximately $479 \mathrm{~km}^{2}$. In this area, incidences of HEC have been reported and seem to have been associated with land use/ cover changes over the past thirty years [16]. Our main focus was on three divisions (Mengwe, Mashati, and Tarakea) where most HEC cases had been reported over the recent decade. Annual rainfall varies with elevation and exposure, ranging from $200 \mathrm{~mm}$ at 800 masl in the lowlands to $3,000 \mathrm{~mm}$ at 2,100 masl on the settlement area bordering KINAPA. Rainfall is bimodal with long rains from March to June and short rains from November to December, which also defines the two cropping seasons of the area. The main economic activities are agriculture (90\%) and small businesses (7\%) and 3\% are employed workers in different sectors [14]. The local communities mainly cultivate crops including coffee (Coffea arabica), banana (Musa sp), maize (Zea mays), and common beans (Phaseolus vulgaris). Human population in Rombo District is about 260,963 people, having increased by $30 \%$ between 1988 and 2012 [14]. About 32\% of the land is used for cultivation, approximately $10 \%$ is for pasture, and $58 \%$ is protected forest [14]. Up to five decades ago, elephants and other large mammals migrated between TWNP and KINAPA through Rombo and occurred at high numbers in Rombo, particularly in the southern part of Kilimanjaro and in the lowland areas bordering TWNP [17]. The population of elephants had been decreasing in this area and was estimated to be 450 in 2010 [18] in the KINAPA ecosystem while an estimate of 2,142 elephants was recently recorded in TWNP [13].

2.2. Study Design and Data Collection. In assessing the spatiotemporal interactions between elephant and human, a reconnaissance survey was conducted in Rombo area. The survey encompassed interviews, participant observations, and use of archive data to get an overview of this interaction for area. The reconnaissance results were able to give us the long-term historical information on the elephant-human interactions in the area and further guided to focus on the areas (where these interactions are apparently challenging) as target for main field data collection (Figure 1).

We collected primary data through semistructured interviews in three divisions following the nature and extent of occurrence of HEC as per Rombo District Wildlife Office records spanning six years (2006-2011). Respondents comprising at least $5 \%$ of the total number of households per village were randomly selected from the studied divisions (Mengwe, Mashati, and Tarakea), irrespective of whether there are HEC victims or not, summing up to 261 households interviewed in Rombo area. Households selected randomly were located at least $0.5 \mathrm{~km}$ to $1 \mathrm{~km}$ apart, and their location was recorded using a handheld GPS (Garmin eTrex). A semistructured questionnaire was administered to respondents aged 25 years and above, who had lived in the respective location for at least five years or more. The information to be 


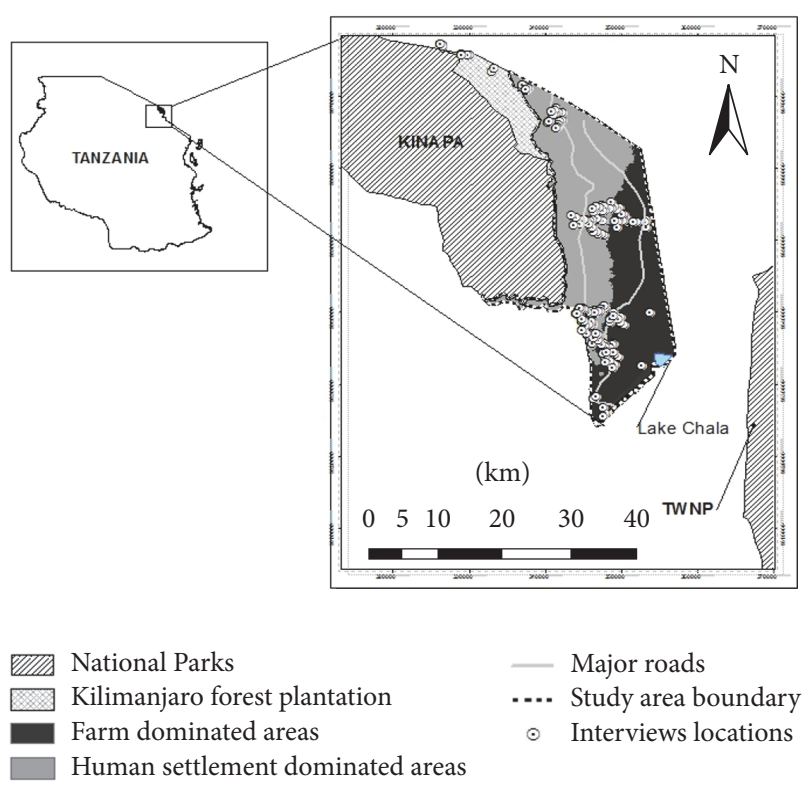

FIGURE 1: Map of Rombo District showing the core study area in northeastern Tanzania surrounded by the two protected area: Kilimanjaro National Park (KINAPA) and Tsavo West National Park (TWNP).

captured included presence of wildlife species on the different land use types (farms, settlement, roads, grazing areas, and watering points), frequency, daytime, season of elephant visits, and the costs of crops lost. Field visits were combined with questionnaire data found across the entire study area and the detailed quantification of the losses was calculated across the three study divisions (Mengwe, Mashati, and Tarakea). This information was further validated with the data from the village meetings and the District Records. Current and historical (2009-2015) levels of HEC in the area were obtained through interviews and through secondary data from Rombo District Wildlife Office (2006-2011). Additionally, village meetings were conducted and at least 20 people per village were selected by their village leaders to be involved in meetings. These included village leaders, elders, and influential people within the villages. Some expert interviews with the District Wildlife Officer and District Agriculture Officer were also conducted. Secondary data on problem wild animals over the past six years (between 2006 and 2011) were collected from the Rombo District Natural Resource Office. These data included 387 recorded incidents with information on the (1) place where the incidence occurred, (2) wild animal species responsible, (3) number of wild animals killed, injured, and chased away, (4) crop types affected, destroyed acres, and estimated cost, (5) livestock type, number injured, number killed, and estimated costs, and (6) people injured or killed.

2.3. Data Analysis. HEC hotspots (Getis-Ord Gi*) analysis tool was used to generate HEC hotspot map. The HEC incidences from records and household surveys data were ranked based on their extent (frequency and magnitude/severity) and this ranged from the magnitude of zero (coldest/no conflict) to six (hottest/most conflict hotspot). Then the GPS coordinates for each of the HEC extents were taken and were used as input features and overlaid on the digital map of Rombo area. We considered an area to be an HEC hotspot when the frequency of incidents was reported to occur for at least three out of six years. The spatial analysis was performed using Geographical Information System (ArcGIS 10.4), where GPS coordinates were imported into Arc map and these were georeferenced to the World Geographical System (WGS) 1984 coordinate system and projected to Universal Transverse Mercator (UTM) Zone 37S prior to analysis. To convert point data to raster data inverse distance weighted (IDW) interpolation tool was used. The in-depth information obtained based on people's perceptions and attitudes was analyzed qualitatively. Multiple response analysis and cross tabulation were performed using Statistical Package for Social Science (SPSS 21). Chi-square heterogeneity test was conducted on the frequency of reported HEC in all study divisions for all years and the types of conflicts that were reported in Rombo over the consistent past six years. The costs for crop losses were measured by the average market price of the crops lost within a particular land area over the last two cropping seasons. The average annual currency exchange rate (1 USD $=2100$ Tsh.) was used to convert Tanzanian shillings to USD.

\section{Results}

3.1. Wild Animals Interacting with Locals. The total numbers of 261 households were surveyed and various wild animals were mentioned to interact with the local people in the study area. Elephants were observed to be frequent visitors in human dominated areas and were perceived by most of the local people $(87.0 \%)$ to be most dangerous, followed by vervet monkey (Chlorocebus pygerythrus) with 5.6\% (Table 1), a result that was confirmed by $95 \%$ of participants in focus group discussions that mentioned elephants to be more dangerous (to people, livestock, and crops on the farm) than other wild animals in the area. Respondents further narrated that in this area other wild animals like baboon and monkeys are not commonly endangering human lives or livestock and even the destruction of crops is minor compared to that by elephants. This also agrees with the District Records, whereby the dominant incidents were reported to be caused by elephants (96\%), buffaloes (Syncerus caffer) (3.5\%), and olive baboon (Papio cynocephalus) (0.5\%).

3.2. HEC Incidents Recorded in the Study Area. Out of 261 respondents, $80 \%$ claimed to have been victims of HEC while $20 \%$ declared to never have been affected by elephants. In total, 387 incidents of HEC throughout Rombo were reported to the Wildlife Division office over the last six years, with most incidents occurring in Mengwe and Mashati. The HEC frequency differed significantly across all divisions over six years $\left(X^{2}=185.16, d f=4\right.$, and $\left.P<0.0001\right)$. Mengwe $(38 \%)$ was most often visited by elephants, followed by Mashati (33\%) and Tarakea (18\%), while Useri (9\%) and Mkuu (2\%) were the least frequently visited. 
TABLE 1: Frequency of visit and perceived threats by local people on the wild animals in Rombo area.

\begin{tabular}{lcccc}
\hline Animal & Scientific name & Number of respondents & Frequency of visit (\%) & Perception of danger (\%) \\
\hline Elephant & Loxodonta africana & 208 & 61.7 & 87.0 \\
Vervet monkey & Chlorocebus pygerythrus & 39 & 11.6 & 5.6 \\
Olive baboon & Papio cynocephalus & 37 & 11.0 & 4.3 \\
Buffalo & Syncerus caffer & 22 & 6.5 & 1.3 \\
Warthog & Phacochoerus africanus & 6 & 1.8 & 1.3 \\
Guinea fowl & Numida meleagris & 2 & 0.6 & 0.4 \\
Wildebeest & Connochaetes gnou & 1 & 0.3 & 0.0 \\
Zebra & Equus quagga & 20 & 5.9 & 0.0 \\
Dove & Streptopelia roseogrisea & 2 & 0.6 & 0.0 \\
\hline Total & & 337 & 100.0 & 100.0 \\
\hline
\end{tabular}

TABLE 2: Records and responses of human-elephant conflict (HEC) incidents (in number and percentages) in Rombo over the last six years.

\begin{tabular}{|c|c|c|c|c|c|}
\hline & Damage & HEC incident (recorded) & Subtotal (\%) & HEC incident (respondents) & Subtotal (\%) \\
\hline \multirow{2}{*}{ Human } & Deaths & 2 & \multirow{2}{*}{$3(0.5 \%)$} & 2 & \multirow{2}{*}{$4(0.4 \%)$} \\
\hline & Injuries & 1 & & 2 & \\
\hline \multirow{15}{*}{ Crop raiding } & Cowpea & 43 & \multirow{15}{*}{$682(99 \%)$} & 71 & \multirow{15}{*}{$1195(99 \%)$} \\
\hline & Finger millet & 75 & & 181 & \\
\hline & Maize & 171 & & 221 & \\
\hline & Pigeon pea & 96 & & 180 & \\
\hline & Irish potatoes & 14 & & 27 & \\
\hline & Banana & 87 & & 178 & \\
\hline & Sunflower & 91 & & 49 & \\
\hline & Cassava & 56 & & 70 & \\
\hline & Sweet potatoes & 0 & & 7 & \\
\hline & Ground nuts & 10 & & 76 & \\
\hline & Watermelon & 0 & & 5 & \\
\hline & Papaya & 20 & & 85 & \\
\hline & Tomato & 0 & & 3 & \\
\hline & Oranges & 0 & & 4 & \\
\hline & Mango & 19 & & 38 & \\
\hline \multirow{2}{*}{ Livestock } & Killed & 1 & \multirow{2}{*}{$2(0.4 \%)$} & 2 & \multirow{2}{*}{$4(0.4 \%)$} \\
\hline & Injured & 1 & & 2 & \\
\hline \multirow[t]{2}{*}{ Water tap } & Destroyed & 1 & $1(0.1 \%)$ & 2 & $2(0.2 \%)$ \\
\hline & Total & 688 & & 1205 & \\
\hline
\end{tabular}

Note. Recorded incidents exceeded 387 due to multiple destruction per incident.

3.3. Types of HEC Incidents Recorded in the Study Area. The types of conflicts differed significantly within Rombo over the past years $\left(X^{2}=797.08, d f=4\right.$, and $\left.P<0.0001\right)$ based on the records, with crop raiding being by far the major type of conflict in records and during interviews (Table 2). Human and livestock death or injury occurred very rarely (Table 2). Across the three study divisions, two people had been killed, one from Mengwe (a woman along the road near her home) and another from Mashati (a man who was drunk). Based on the recorded HEC cases, interviews and meetings, maize (Zea mays) was the most dominant crop raiding target, followed by pigeon pea (Cajanus cajan), finger millet (Eleusine coracana), and banana (Musa sp.) (Table 2).
3.4. Season and Costs of HEC Incidents in the Study Area. From the records, conflicts occurred most frequently (in $80 \%$ of the cases) between May and July while least conflicts (2\%) occurred in January and September, which was similarly reported by interviewees and meetings (Figure 2). From the respondents, the mean area damaged was 4 ha per household, with the destroyed farm sizes ranging from 1.5 ha to 15 ha per household per season. The mean total costs incurred per household per season across three study divisions (Mengwe, Mashati, and Tarakea) were 398 USD, 256 USD, and 284 USD, respectively, and they mainly occurred between May and July. Over the past 6 years of our study, monthly costs due to crop loss as reported to the wildlife authorities ranged from 250 


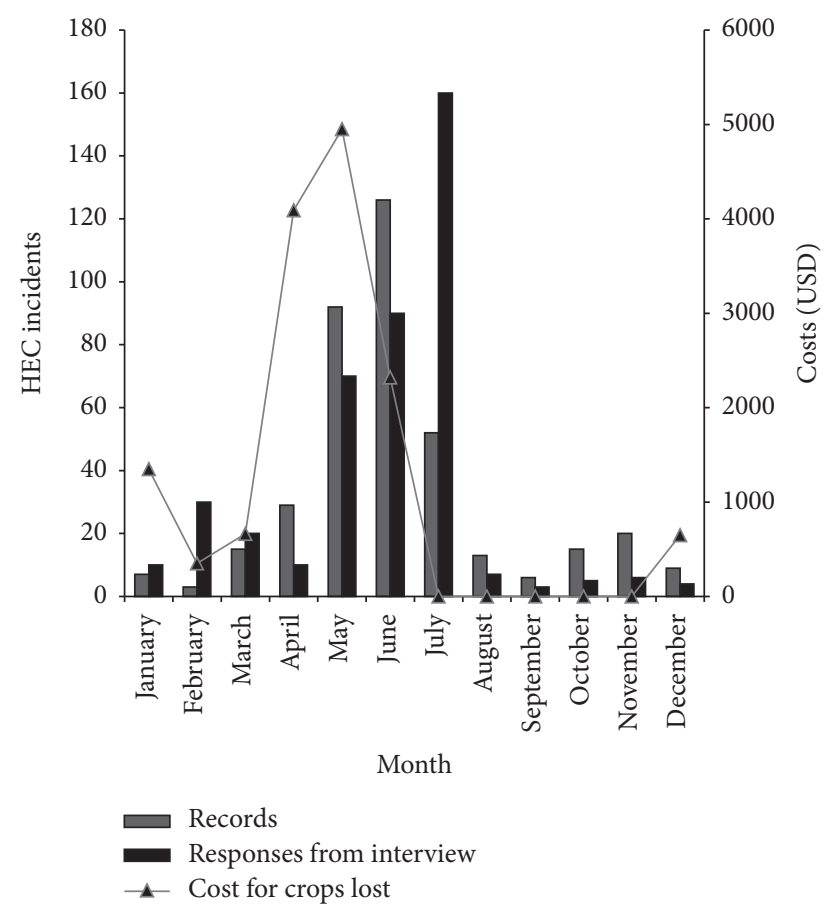

Figure 2: Frequency of human-elephant conflict (HEC) and costs of crop loss across months based on the Rombo District Records (records, $n=387)$ and responses from interviews $(n=261)$ in the Rombo area over the last 6 years.

USD to 5000 USD per household per season (equivalent to 50 USD to 1000 USD per household per month) and occurred between April and June (Figure 2). The District Records and information from wildlife officers indicated that, historically, the elephants migrated from the nearby PAs (mainly TWNP) to KINAPA through Rombo area in groups of mixed age and sex and ranging from 7 to 500 elephants. Depending on their numbers, they damaged crops in the farmers' field in Rombo as they move between the two PAs. During such events, local wildlife authorities have been cooperating with local people to move them away from the farms, sometimes scaring them with the rubber bullets. This approach has been used in tense situations especially during cropping seasons as conflict management option although it is not considered by the local people as a viable option in longer term in the area. The majority of respondents (99\%) explained further that they did not receive any compensation for their losses. Hence, to avoid crop raiding, they even harvest their maize before time (half dried) in June to avoid massive losses in July. Due to this reason, although many elephants incidents reported by respondents occurred in July, the crop loss costs were negligible. From the interviews and meetings, most (95\%) of elephant crop raiding took place during the nights and prolonged till early mornings when elephants were reported to return to the protected areas.

3.5. Local Prevention/Mitigation Measures and Conflict Trends. Frequently used methods to deter elephants included audio instruments (56\%), such as shouting, banging on

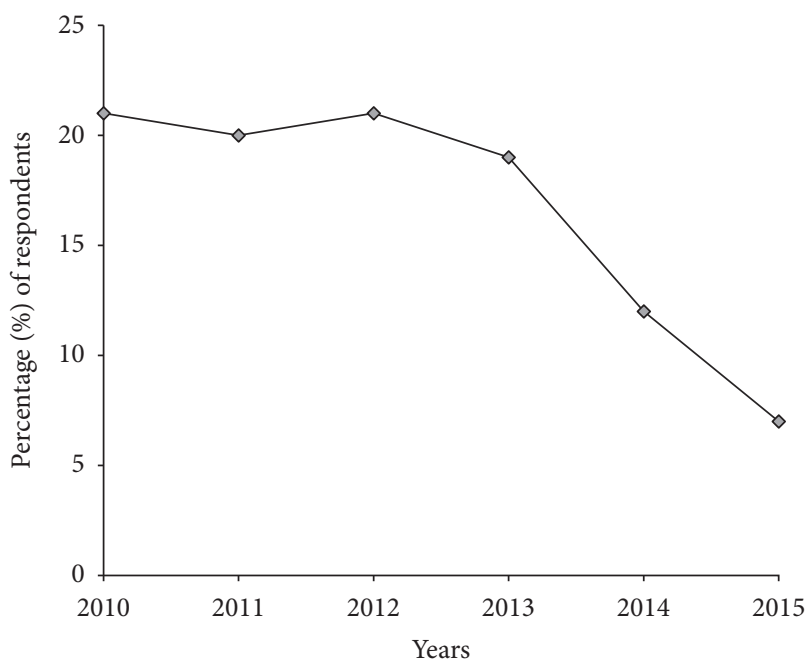

FIGURE 3: Responses of the interviewees on the human-elephant conflict (HEC) incidences over the past six (2010 to 2015) years across the Rombo area.

corrugated iron sheets, tins, and drums whistles. Other HEC mitigation measures as reported by respondents included the use of night visual instruments (24\%, e.g., lighting fires and torch lights), intervention by game rangers (19\%), and guarding fields $(1 \%)$ by the farmers themselves. Respondents claimed that elephants were becoming familiar to the methods, rendering these to be less effective over time. Further, they claimed that the techniques were labourintensive and even included children in the activities. The reported incidents in the District Records indicated a decrease in HEC as 272 cases were reported in 2007 while only 66 cases were recorded in 2011. These records are in agreement with the responses from local people who reported that the overall HEC frequency has declined in Rombo (Figure 3).

3.6. HEC Hotspots across the Study Area. The results show that elephants were highly attracted by crops and, hence, HEC was most common in farm lands compared to other land use areas. The spatial analysis showed that the HEC hotspots in Mengwe and Mashati divisions concentrated at lowland areas, which were dominated by seasonal crops, especially maize, interspersed with only few settlements. From our interview, meetings, and District Records, these lowland areas dominated by farms (particularly in Mengwe and Mashati) were reported to have many conflict incidents and were closer (about 30 to $10 \mathrm{~km}$ ) to TWNP in Kenya. In these two divisions, elephants were reported to come from TWNP and not KINAPA. Therefore, the highland areas closer to KINAPA, dominated by settlement and agroforestry (trees, banana, and coffee), represented HEC cold spots in our map. In Tarakea division, the elephants came from KINAPA and not TWNP. Local people in this area cultivated their seasonal crops in the forest plantations bordering KINAPA (Figure 1). Hence, HEC hotspots concentrated inside the forest plantations (Kamwanga, Endonet, Nalemuru, and Rongai) bordering KINAPA where seasonal crops (mainly maize and 


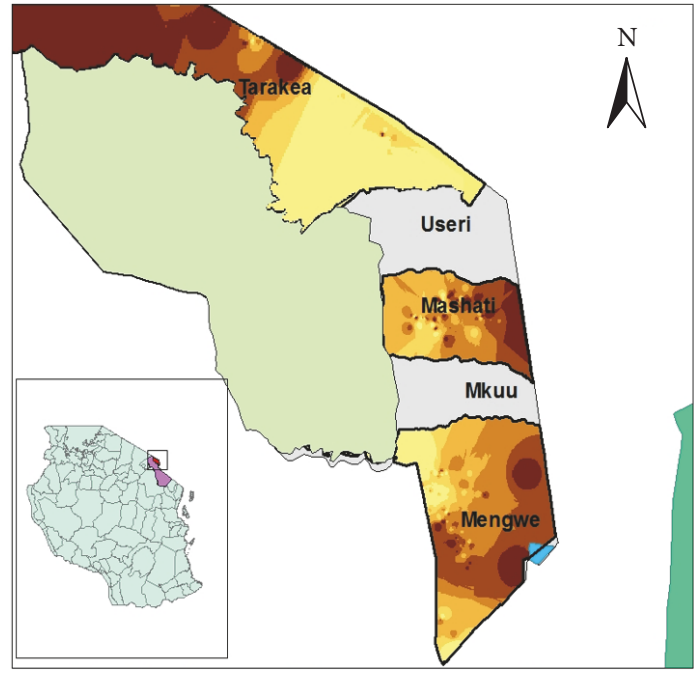

$(\mathrm{km})$

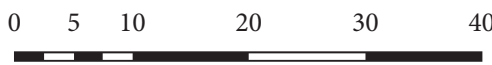

HEC hotspots

0 (very cold)

1 (cold)

2 (slightly cold)

3 (slightly hot)

4 (hot)

5-6 (very hot)

Lake Chala

FIgURE 4: Human-elephant conflict (HEC) spots (ranging from the magnitude of zero [very cold] to six [very hotspot] areas) in Rombo area. The darker areas indicate hotspots. (Only the three most frequently visited areas by elephants (Mengwe, Mashati, and Tarakea) were analyzed.)

Irish potatoes (Solanum tuberosum)) were cultivated. Areas outside the forest dominated by settlement and agroforestry represented HEC cold spots (Figure 4).

\section{Discussion}

4.1. Human Perception, Human-Elephant Conflict Incidents, and Costs. While elephants were perceived as the most dangerous animals in our study area, we also found various other wild animal species to interact with local people. Because of the level of destruction the elephants inflict, ranging from severe crop raiding to killing people, this species was claimed to be most damaging and dangerous $[19,20]$. In some areas, farmers who also grow crops find that elephants and other wildlife can destroy entire swaths of their fields in a single night [21]. Under such circumstances, some people in Rombo abandoned their crops entirely, which is supported by a study in Longido in northern Tanzania, where farmers recently gave up growing crops because elephant damage was so pervasive [22]. In our study, further negative attitudes towards elephants by local people have been attributed to the perception that elephants tend to make top soil less fertile through trampling. Nutrient-rich top soils tend to be eroded and to leach nutrients during heavy rains when herbaceous cover is being removed [23]. However, this perception is in contrast to $[24,25]$ that indicated that elephant dung can increase soil nutrients.

Across the three study divisions, crop raiding was the most frequently recorded and mentioned HEC. This agrees with a study in Zimbabwe, where crops such as maize and sorghum were found to attract elephants [15] while in Ghana cocoa was most attractive [26]; in India, coffee seemed to attract elephants [27] and in Asia paddy [28]. In our study area, $82 \%$ of respondents mentioned maize to be highly preferred by elephants compared to other crops, congruent with findings by $[15,29]$ in Zimbabwe and Tanzania (Serengeti), respectively. In our study area the cases for human mortality by elephants were few, similar to $[20,30,31]$, contrary to a study in Asia where human mortality through elephants was high up to 50 people killed per year [28]. HEC frequency in the study area was strongly seasonal and occurred during crop maturity between May and July. This is similar to studies in Kenya, where crop damage through raiding elephants was highest in August when crops had just matured [32]. We found the costs of crop loss were about 300 USD per ha and the costs per household were about 50 USD to 1000 USD per month. This is relatively high loss compared to other studies like in Cameroon which showed the cost of elephant raiding was 195 USD per ha [33] and in Asia 200 USD per year. Elephant crop raiding (95\%) in this study took place during the nights and early mornings, involving both male and female elephants, similar to our study, which is in contrast to findings by [28] that found that mainly solitary bulls attacked crops in Sri Lanka.

4.2. Human-Elephant Conflicts Hotspot Areas. In our study, in the lowland areas of Mengwe and Mashati, elephants were reported to come from TWNP in Kenya to drink water in Lake Chala, especially during the dry season, and then invaded the nearby crop fields. In Tarakea, the elephants that caused conflicts were mentioned to be coming from KINAPA, which is the nearest protected area from the farmland. The studies conducted by $[19,26]$ also concluded that it might be expected that the proximity of a village or field to a protected area increases the likelihood of being affected by elephants and other wild animals. Our findings indicated that HEC hotspots were found to be highest in Mengwe and Mashati divisions (about $10 \mathrm{~km}$ from TWNP) with human population densities of 272 and 318 per $\mathrm{km}^{2}$, respectively. These densities are almost six times the national population density of 57.3 people per $\mathrm{km}^{2}$ [14]. The growth of the human population around PAs may have negative impacts on large mammals and biodiversity through illegal hunting, deforestation, and habitat encroachment $[34,35]$ which ends up with blockage of migratory routes.

We also found that in Rombo most HEC hotspots were in farmlands adjacent to protected areas, which is in agreement with $[15,19,22,29,36]$ that found high HEC adjacent to protected areas and within migratory routes. As much as humans' activities like agriculture affect large mammal (e.g., elephant) abundance and distribution through habitat loss and poaching/overhunting, people and livestock also 
compete with wildlife for resources such as plant-derived forage, water, and minerals, resulting in various conflicts. During the data collection in the field, our participatory observations indicated that land use is rapidly changing in Rombo [16] and wildlife habitats are declining fast. The low to medium elevation areas of Rombo received moderate annual rainfall $(500 \mathrm{~mm})$ and, thus, the prospect of growing some crops as well as more settlements being developed is imminent. HEC cold spots were far away from protected areas and in highlands dominated by settlements and agroforestry, with planted trees and perennial crops like banana and coffee. While some studies in India show that elephants like coffee [27] and around Serengeti, Tanzania, like banana [29], responses in our study showed that elephants do not often raid coffee or banana but rather prefer maize (Table 2).

4.3. Human-Elephant Conflict Trends. In our study, the HEC had decreased over the last six years. This is in contrast to other studies: [8] reported an increase in HEC ten years ago in Zimbabwe. Also, [27] recorded an increase of HEC intensity over the last 10 years in India, all of which were accompanied with a human population increase and the expansion of farms. Contrary to this, although the human population has been growing and farms and settlements have expanded in the Rombo area [14, 16, 37], HEC is declining. This might be caused by the continued land use land cover changes coupled with an increase in human population in the nearby protected areas surrounding the farmland of the Rombo area, which might suppress elephants coming out of their protected areas by blocking their migratory routes. Decreasing HEC incidents might also be caused by a decreasing elephant population in the KINAPA ecosystem. Up to five decades ago, elephants and other large mammals migrated between TWNP and KINAPA through Rombo and occurred in high numbers in Rombo, particularly in the southern part of Kilimanjaro and in the lowland areas bordering TWNP [17]. Due to increasing habitat fragmentation, encroachment, and poaching for ivory trade, some studies reported a declining elephant population in the KINAPA ecosystem. For instance, in the 1970s, the population was about 1200 elephants [10] and decreased to about 750 in 2003 [38] and further to 450 in 2010 [18] while an estimate of 2,142 elephants was recently recorded in TWNP [13]. Due to the blockage of the migratory routes in recent decades, elephants are coming from TWNP and raid crops in lowland areas of Rombo and go back to TWNP. In upland areas, elephants come out from KINAPA, raid the crops planted inside the forest plantation, and go back to KINAPA [16, 37].

4.4. Human Population and Its Implication to Elephant Conservation. The historical distribution of elephants and large mammals in Rombo area has been linked to human settlements which largely occurred between 1930 and 1965 and reduced the elephant distribution range to few migratory elephant groups that would enter KINAPA from TWNP in the east $[10,17]$. This means that migration by elephants and other mammals used to occur on a regular basis between KINAPA and TWNP in Kenya to the east but very little evidence was found that this migration still existed in this study. The number of people in Rombo District has increased by $30 \%$ over the past 25 years $[14,37]$ and this is likely to have increased competition with wildlife. Generally, savannas with high human populations also have high livestock numbers, farming activities, and settlement [22]. More people can also mean more hunting pressure and, thus, more wildlife deaths $[22,34]$. However, from an anthropocentric point of view conflicts with wildlife decrease as human populations rise and shift to smaller, less dangerous species, simply because the larger species disappear $[22,37]$. This might be true for Rombo area, where there has been a decline in elephant population in KINAPA by approximately $43 \%$ between 2003 and $2010[6,38]$. In this area, humans have been competing with elephants by converting their habitat into farmland where they grow perennial and seasonal crops such as bananas, coffee, and maize [16]. Therefore to attain elephant conservation and livelihood development, it is necessary to consider human population growth and distributions as the key factor and come up with alternative land use plans.

\section{Conclusion}

Given that no ecological study has ever been conducted in Rombo area, this is a new ground evidence generated from the data. It also becomes the new beginning of sciencebased evidence to policy makers on how they can balance the trade-offs between elephant conservation and human development. Our assessment of the nature and the extent of HEC and its impact on conservation efforts provides important information to conservationists that are to meet the challenges related to biodiversity loss. We showed that HEC hotspots are located in areas adjacent to PAs and coincided with seasonal crop maturity especially maize in the lowlands. Short-term management measures such as the introduction of alternative crops which are not attractive to elephants to reduce HEC should be prioritized in areas bordering the PAs. Damage prevention should focus on the seasonal crop like maize maturity and harvesting months. Our study also showed that HEC incidents were declining over the last six years, despite increasing human settlements and agricultural activity. Although we do not know how many people this area can support without strongly diminishing wildlife populations, patterns of human populations should be taken into account when planning for long-term HEC mitigation measures. Buffer zones may also be established in such areas where human and wildlife coexistence is likely to occur. Local people may benefit from coexistence if the mechanisms for sharing the profits from wildlife tourism, for example, are in place. Our study shows how various locally collected data in combination with socioecological assessments, interviews, and long-term records can successfully be applied to help highlighting HEC hotspots and predicting their spatial and temporal occurrence.

\section{Conflicts of Interest}

The authors declare that there are no conflicts of interest regarding the publication of this paper. 


\section{Acknowledgments}

The authors thank Mr. A. L. Massawe, the Wildlife Officer of Rombo District, for providing secondary data on elephant conflict incidences in Rombo District, as well as the Village Executive Officers E. J. Mtei, Mr. G. J. Kauki, C. Gwandu, and M. Mwanyange for their support in the field. They further thank S. Terengia for support in spatial analysis and $\mathrm{H}$. A. Msuya, M. Iddy, and N. E. Msuya for assisting during data collection. This work was supported by the Government of Tanzania through the Commission for Science and Technology $(\mathrm{COSTECH})$ and the German Academic Exchange Service (DAAD) as part of a Ph.D. scholarship.

\section{References}

[1] S. M. Redpath, J. Young, A. Evely, W. M. Adams, W. J. Sutherland, A. Whitehouse et al., "Understanding and managing conservation conflicts," Trends in Ecology \& Evolution, vol. 28, pp. 100-109, 2013.

[2] R. E. Hoare and J. T. Du Toit, "Coexistence between people and elephants in African savannas," Conservation Biology, vol. 13, no. 3, pp. 633-639, 1999.

[3] N. W. Sitati, M. J. Walpole, R. J. Smith, and N. Leader-Williams, "Predicting spatial aspects of human-elephant conflict," Journal of Applied Ecology, vol. 40, no. 4, pp. 667-677, 2003.

[4] M. Mutinda, G. Chenge, F. Gakuya et al., "Detusking fencebreaker elephants as an approach in human-elephant conflict mitigation," PLoS ONE, vol. 9, no. 3, Article ID e91749, 2014.

[5] M. Y. Said, J. O. Ogutu, S. C. Kifugo, O. Makui, R. S. Reid, and J. de Leeuw, "Effects of extreme land fragmentation on wildlife and livestock population abundance and distribution," Journal for Nature Conservation Elsevier GmbH, vol. 34, pp. 151-164, 2016.

[6] S. Mduma, A. Lobora, C. Foley, and J. Trevor, "Tanzania elephant management plan," Tanzania Wildlife Research Institute, 2010.

[7] WCS, "Human Elephant Conflict Mitigation in Tanzania," Wildl Conserv Soc Tanzania Program, 2009.

[8] R. E. Hoare, "Vertically integrated Human-Elephant conflict management system in Tanzania: background and next steps," Human-Elephant Confl Rev Case Stud, pp. 1-12, 2007.

[9] R. R. Hoffmeier-Karimi and B. A. Schulte, "Assessing perceived and documented crop damage in a Tanzanian village impacted by human-elephant conflict (HEC)," Pachyderm, vol. 2015, pp. 51-60, 2015.

[10] T. A. Afolayan, "Effects of elephant activities on forest plantations in the kilimanjaro forest-game reserve in northern Tanzania," Oikos, vol. 26, pp. 405-410, 1975.

[11] S. Wasser, J. Poole, P. Lee et al., "Elephants, Ivory, and Trade," Science (80-), vol. 327, pp. 1331-1332, 2010.

[12] Y. Chen, J. Marino, Y. Chen, Q. Tao, C. D. Sullivan, K. Shi et al., "Predicting hotspots of human-elephant conflict to inform mitigation strategies in xishuangbanna, southwest China," PLOS ONE, vol. 11, Article ID e0162035, 2016.

[13] S. Ngene, S. Njumbi, M. Nzisa, K. Kimitei, J. Mukeka, S. Muya et al., "Status and trends of the elephant population in the Tsavo-Mkomazi ecosystem," Pachyderm, vol. 53, pp. 38-50, 2013.

[14] URT, "Population and housing census, population distribution by administrative areas," 2013 .
[15] R. E. Hoare, "Determinants of human-elephant conflict in a land-use mosaic," Journal of Applied Ecology, vol. 36, no. 5, pp. 689-700, 1999.

[16] N. E. Mmbaga, L. K. Munishi, and A. C. Treydte, "ow dynamics and drivers of land use/land cover change impact elephant conservation and agricultural livelihood development in Rombo, Tanzania," J Land Use Sci. Taylor \& Francis, vol. 12, pp. 168-181, 2017.

[17] G. Child, "Some notes on mammals of Kilimanjaro," Tanganyika Notes and Records, vol. 64, pp. 77-89, 1965.

[18] D. G. Mpanduji and K. Ngomello, "Elephant movements and home range determinations using GPS/ARGOS satellites and GIS programme: Implication to conservation in southern Tanzania," in Proceedings of the 6th TAWIRI Annual Scientific Conference, pp. 1-15, 2007, http://www.selous-niassa-corridor .org/filead min/publicatio ns/SNWC__elephant_movements_ and_home_range_determinations.pdf.

[19] M. D. Graham, I. Douglas-Hamilton, W. M. Adams, and P. C. Lee, "The movement of African elephants in a human-dominated land-use mosaic," Animal Conservation, vol. 12, no. 5, pp. 445-455, 2009.

[20] A. Chang'a, N. de Souza, J. Muya et al., "Scaling-up the use of chili fences for reducing human-elephant conflict across landscapes in Tanzania," Tropical Conservation Science, vol. 9, no. 2, pp. 921-930, 2016.

[21] S. Gubbi, "Patterns and correlates of human-elephant conflict around a south Indian reserve," Biological Conservation, vol. 148, no. 1, pp. 88-95, 2012.

[22] R. S. Reid, Savannans of our birth: People, wildlife and change in East Africa, University of Califonia. Press, London, UK, 2012.

[23] R. Liu, J. Wang, J. Shi et al., "Runoff characteristics and nutrient loss mechanism from plain farmland under simulated rainfall conditions," Science of the Total Environment, vol. 468-469, pp. 1069-1077, 2014.

[24] J. Metsio Sienne, R. Buchwald, and G. Wittemyer, "Differentiation in mineral constituents in elephant selected versus unselected water and soil resources at Central African bais (forest clearings)," European Journal of Wildlife Research, vol. 60, no. 2, pp. 377-382, 2014.

[25] G. E. Soka and M. E. Ritchie, "Land-Cover legacy effects on arbuscular mycorrhizal abundance in human and wildlife dominated systems in tropical savanna," Advances in Ecology, vol. 2016, 10 pages, 2016.

[26] F. K. Harich, A. C. Treydte, J. Sauerborn, and E. H. Owusu, "People and wildlife: Conflicts arising around the Bia Conservation Area in Ghana," Journal for Nature Conservation, vol. 21, no. 5, pp. 342-349, 2013.

[27] P. Bal, C. D. Nath, K. M. Nanaya, C. G. Kushalappa, and C. Garcia, "Elephants also like coffee: Trends and drivers of human-elephant conflicts in coffee agroforestry landscapes of Kodagu, Western Ghats, India," Environmental Management, vol. 47, no. 5, pp. 789-801, 2011.

[28] C. Santiapillai, S. Wijeyamohan, G. Bandara, R. Athurupana, N. Dissanayake, and B. Read, "An assessment of the humanelephant conflict in Sri Lanka," Ceylon Journal of Science (Biological Sciences), vol. 39, pp. 21-33, 2010.

[29] A. Mwakatobe, J. Nyahongo, J. Ntalwila, and E. Roskaft, "The impact of crop raiding by wild animals in communities surrounding the Serengeti National Park," Int J Biodivers Conserv, vol. 6, pp. 637-646, 2014.

[30] R. Hoare, "African elephants and humans in conflict: the outlook for co-existence," Oryx, vol. 34, pp. 34-38, 2000. 
[31] A. Mwakalobo, A. Kaswamila, and A. Kira, “Tourism Regional Multiplier Effects in Tanzania: analysis of Singita Grumeti Reserves Tourism in the Mara Region," Journal of Sustainable Development, 2016, http://www.ccsenet.org/journal/index.php/ jsd/article/view/50640.

[32] A. J. Sitienei, G. Jiwen, and S. M. Ngene, "Assessing the cost of living with elephants (Loxodonta africana) in areas adjacent to Meru National Park, Kenya," European Journal of Wildlife Research, vol. 60, no. 2, pp. 323-330, 2014.

[33] M. N. Tehamba, "History and present status of the human/ elephant conflict in the Waza-Logone Region, Cameroon, West Africa," Biological Conservation, vol. 75, no. 1, pp. 35-41, 1996.

[34] G. Wittemyer, P. Elsen, W. T. Bean, A. C. O. Burton, and J. S. Brashares, "Accelerated human population growth at protected area edges," Science, vol. 321, no. 5885, pp. 123-126, 2008.

[35] E. Danquah, "Spatial Distribution of Elephants versus Human and Ecological Variables in Western Ghana," Advances in Ecology, vol. 2016, pp. 1-8, 2016.

[36] J. J. Blanc, R. F. W. Barnes, G. C. Craig, H. T. Dublin, C. R. Thouless, I. Douglas-Hamilton et al., "African elephant status report 2007: an update from the African elephant database [Internet]," IUCN Species Survival Commission, 2007.

[37] N. E. Mmbaga, L. K. Munishi, and A. C. Treydte, "Human population growth as indicator for human-elephant conflicts in Rombo area, Tanzania," J Biodivers Environ Sci, vol. 10, pp. 94102, 2017.

[38] L. K. Munishi and S. L. S. Maganga, "The status of the african elephants in mount kilimanjaro ecosystem and its management implication," African Elephant Specialist Group, 2003, Nairobi, Kenya, IUCN/SSC. 

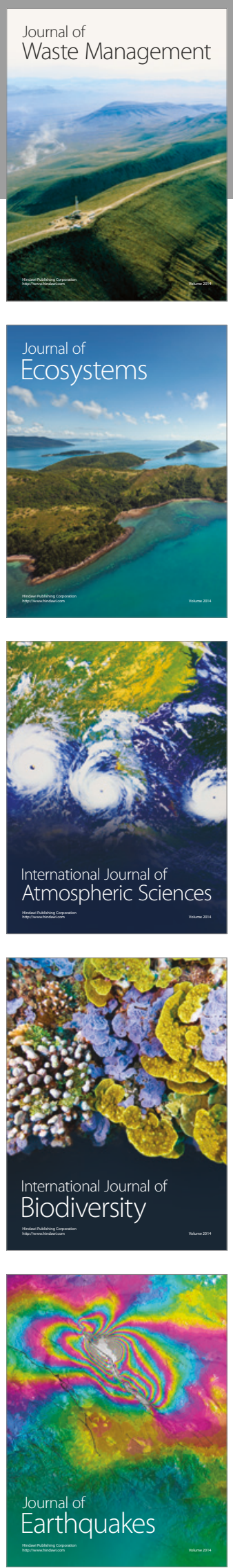
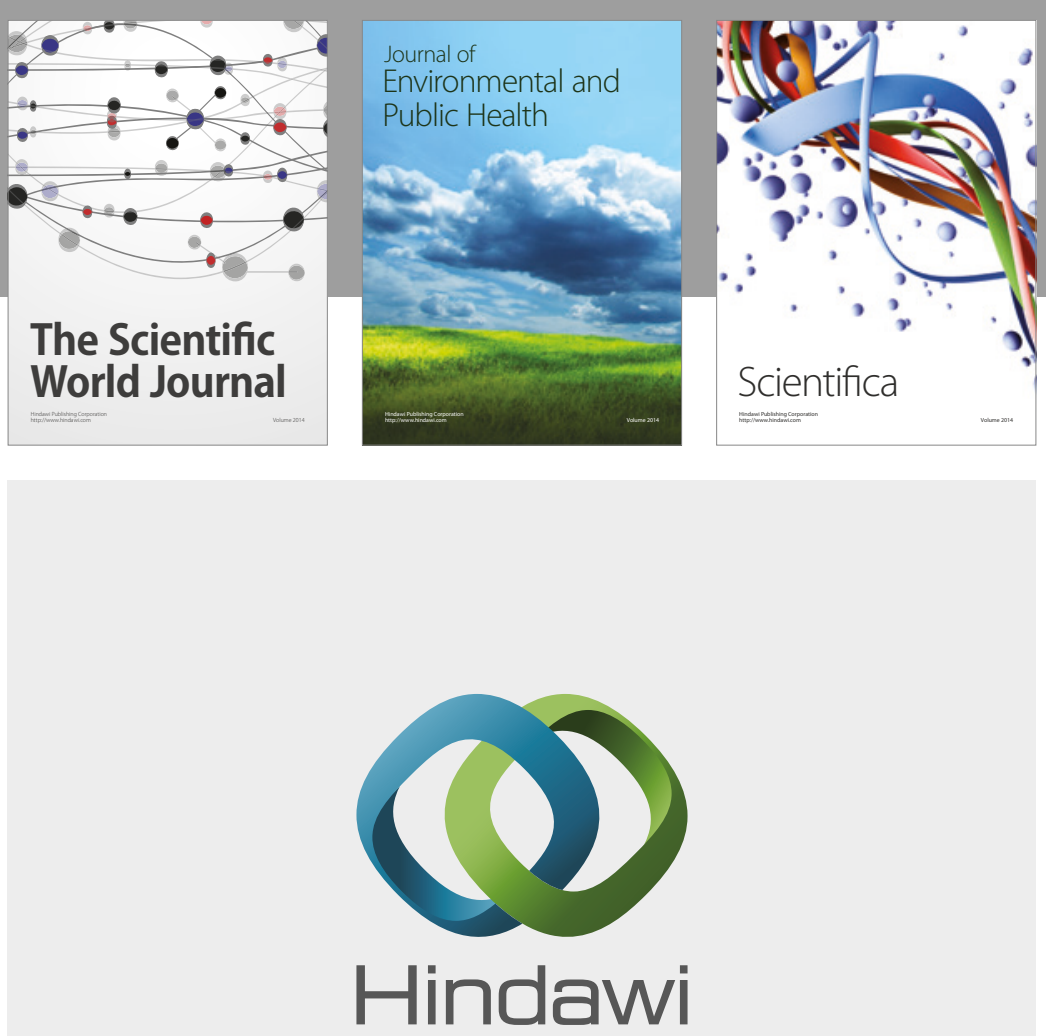

Submit your manuscripts at

https://www.hindawi.com
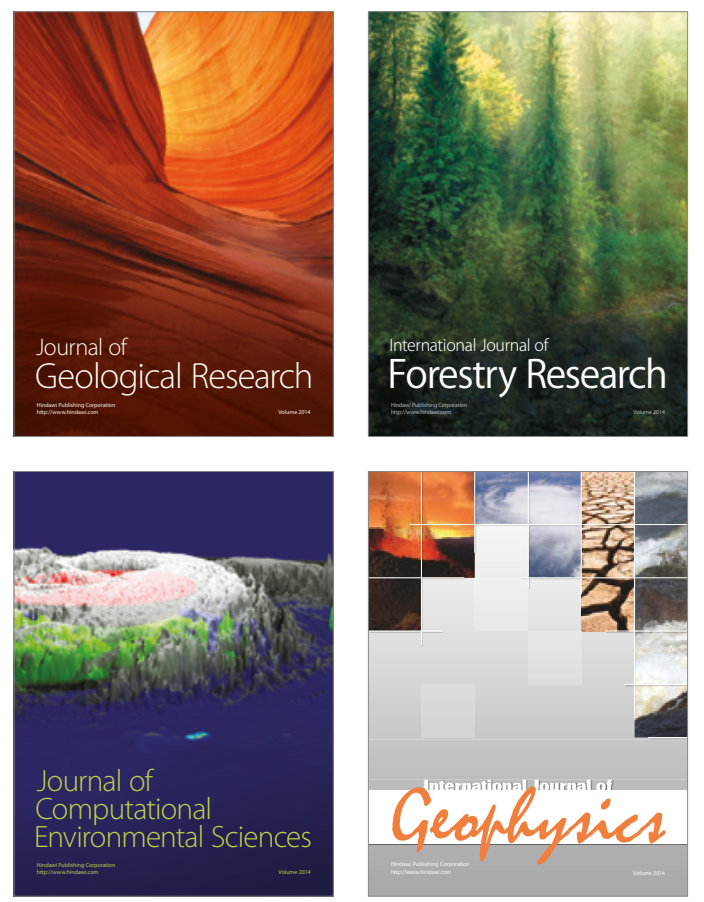
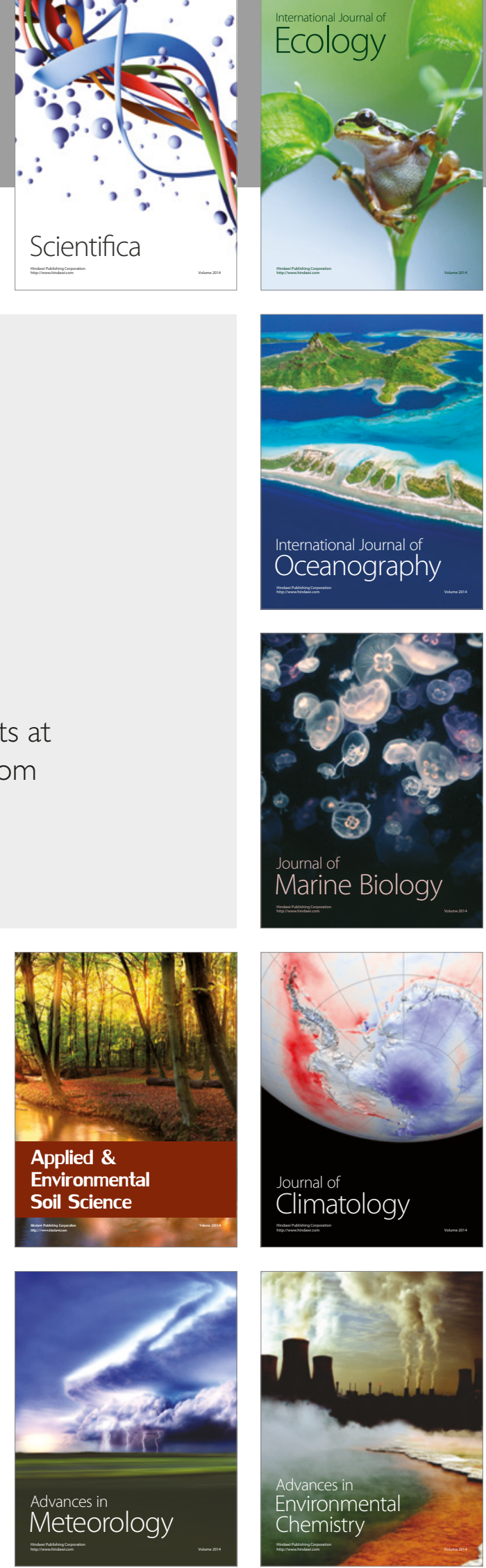